\title{
Real-time impact of power balancing on power system operation with large scale integration of wind power
}

\author{
Abdul BASIT ${ }^{1,2}$, Anca D. HANSEN ${ }^{1}$, Poul E. SØRENSEN ${ }^{1}$, \\ Georgios GIANNOPOULOS ${ }^{3}$
}

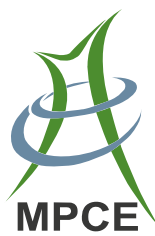

\begin{abstract}
Highly wind power integrated power system requires continuous active power regulation to tackle the power imbalances resulting from the wind power forecast errors. The active power balance is maintained in real-time with the automatic generation control and also from the control room, where regulating power bids are activated manually. In this article, an algorithm is developed to simulate the activation of regulating power bids, as performed in the control room, during power imbalance between generation and load demand. In addition, the active power balance is also controlled through automatic generation control, where coordinated control strategy between combined heat and power plants and wind power plant enhances the secure power system operation. The developed algorithm emulating the control room response,
\end{abstract}

CrossCheck date: 4 February 2015

Received: 7 July 2014 / Accepted: 13 January 2015 / Published online: 2 November 2015

(C) The Author(s) 2015. This article is published with open access at Springerlink.com

$\triangle$ Abdul BASIT

a_basitkhan@hotmail.com

Anca D. HANSEN

anca@dtu.dk

Poul E. SØRENSEN

posq@dtu.dk

Georgios GIANNOPOULOS

Georgios.Giannopoulos@elia.be

1 Department of Wind Energy, Technical University of Denmark, Frederiksborgvej 399, 4000 Roskilde, Denmark

2 Sino-Danish Center for Education and Research, Niels Jensens Vej 2, 8000 Aarhus, Denmark

3 ELIA SYSTEM OPERATOR, Keizerslaan 20, 1000 Brussels, Belgium to deal with real-time power imbalance, is applied and investigated on the future Danish power system model. The power system model takes the hour-ahead regulating power plan from power balancing model and the generation and power exchange capacities for the year 2020 into account. The real-time impact of power balancing in a highly wind power integrated power system is assessed and discussed by means of simulations for different possible scenarios.

Keywords Wind power plant (WPP), Simulation power Balancing model (SimBa), Centralised or de-centralised combined heat and power plant (CHP or DCHP), Automatic generation control (AGC), Rolling balance

\section{Introduction}

Increasing wind power integration influences the technical operation of a power system, particularly the active power balance control between generation and demand. The variable wind power generation together with the technical capabilities of the generating units and the market rules might hinder the power system balance control. These factors must be taken into account while planning the power balancing operation of a large scale wind power integrated power system.

Transmission System Operators (TSOs) have to securely operate the power system in transporting the generated electricity to the end consumers. In deregulated power systems, the electricity is traded in electricity markets by the balance responsible companies that can produce, consume or retail. Examples of electricity markets are the dayahead (DA), intraday and regulating power markets [1]. The balance responsible trades in DA market and balance the power system for each operating period in the next day. If the power system comes out of balance on an operating 
day, owing to the update of wind power forecasts or the unavailability of power plants, the balance responsible trades again in intraday market for every operating period to one hour in advance of the actual operation hour. The intraday market balances the power system. However wind power forecast errors and other non-contingent events might create power imbalance within the actual operating hour. These imbalances are then minimized by activating the power bids, within minutes, from regulating power market. The TSOs select the dispatch bids with the foremost intent of preserving system integrity with minimum production cost.

With increasing large scale integration wind power, active power balancing is becoming a challenging technical issue. Several studies have been performed in this area over the last few years. For example, according to [2], the increasing integration of wind power alters the frequency behaviour and solutions must be developed to meet these challenges. A Dutch case study in [3] shows that additional regulating reserves are required in the presence of large scale wind power. The Chinese studies in [4] have led to the conclusion that the fluctuation from WPPs can be controlled via conventional generators. According to [5], the WPPs can participate in frequency regulation services with energy storage devices such as super capacitor banks, while [6] examines the benefits of active power regulation from WPPs. However to enhance the operational security of the power system, further studies on the system level is the need of the hour.

Real-time control of the regulating power is necessary for reliable and secure operation of future power system with large scale wind power integration. The objective of this article is to study how active power balance can be controlled in real-time with coordinated automatic generation control (AGC) action between combined heat and power plants (CHPs) and wind power plants (WPPs) and by activating the regulating power bids, as performed in the control room. For this purpose, an algorithm named as "rolling balance" has been developed for this study which emulates the real-time control room response while activating the regulating bids.

To study the real-time active power balance control in a power system with high wind power penetration level, the rolling balance is exemplified on the future Danish power system corresponding to year 2020, where $50 \%$ of the total electricity production has to be supplied by wind power [7]. The balanced regulating power plan, in a 5 min resolution, for generation and power exchange with neighbouring power systems is provided by hour-ahead (HA) power balancing program. However, wind power forecast errors and other events might cause a power imbalance in the real time, which can be partially compensated by activating the additional regulating power with a rolling balance and the coordinated AGC response. The rolling balance activates the regulating power from CHPs, to minimize the real time power imbalance in the power system.

The article is organised as follows. First the dynamic power system model is described. The active power balancing models and the proposed algorithm "rolling balance" are then presented and explained. The performance of the rolling balance and the AGC is then assessed through simulations for the year 2020 with high wind penetration scenarios and the conclusive remarks are reported at the end.

\section{Dynamic power system model}

As aforementioned, the Danish power system is used to validate the performance of the rolling balance and the AGC. The Danish power system is composed of Eastern and Western Danish power systems, which are synchronously connected to the Nordic and Continental European (CE) synchronous power systems, respectively [8]. To study the active power balance control in the Danish power system, it requires a detailed dynamic representation of the power system that includes conventional power plants, WPPs and interconnection with neighbouring power systems. The system interconnections and the aggregated power plants models, developed in power factory, are explained below.

\subsection{System interconnection}

As depicted in Fig. 1, the Eastern and Western Danish power systems are connected through an high voltage direct current (HVDC) connection, i.e. Great Belt Link (GBL) having a transmission capacity of $600 \mathrm{MW}$. The Danish power systems are also connected to the strong neighbouring power systems of Nordic and CE, which are offering large frequency bias factor [9]. The Eastern Danish power system is synchronized with the Nordic power system through Sweden, whereas the Western Danish power system is synchronized via Germany with the CE power system.

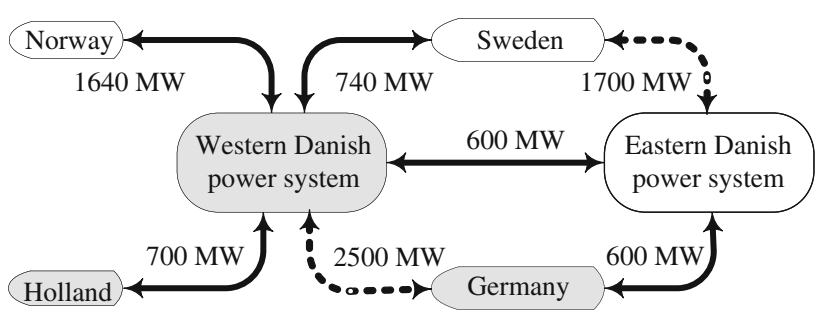

Fig. 1 Danish power system interconnections 
Figure1 shows the interconnection capacities of the Danish power system with its neighbouring powers planned for the year 2020 [10]. The AC interconnection is shown as a solid line and the DC interconnection with solid line and diode symbol. In this study, the system interconnections are modelled as load where the export power can be seen as positive load and the import power as negative load. Moreover, an external grid based on the recommendation for $\mathrm{CE}$ and Nordic power systems is modelled to study the dynamics on AC interconnections [11, 12].

\subsection{Power plants modelling}

The electrical power generation in Denmark is a combination of conventional and renewable generation sources. The conventional power generation is typically from CHPs and de-centralised combined heat and power plants (DCHPs), while renewable generation is primary based on WPPs contribution. In this study, aggregated models for conventional power plants and WPPs are implemented, as they have the advantage of reduced computation effort, while still containing dynamic features relevant for long term dynamic simulation studies. These aggregated models are developed based on description found in [8, 13-16] and takes the information from HA power balancing model, rolling balance and the AGC for power generation set points.

\subsubsection{Combined heat and power plant model (CHP)}

An aggregated CHP model is developed based on studies in $[13,14]$, to examine the dynamic features of a power plant in long term dynamic simulation studies, which may affect the system stability due to its slow boiler response. The response time and ramp rates associated with CHP are in order of minutes and are the dominant characteristic for power system studies.

A generic diagram of an aggregated CHP model consisting of a thermal boiler, a boiler turbine controller, a steam turbine and a speed governor, is illustrated in Fig. 2. The boiler model takes into account the practical limits of the turbine output and the delays associated with the stored steam energy, while the steam turbine introduces the delays associated with the valve movement and change in the

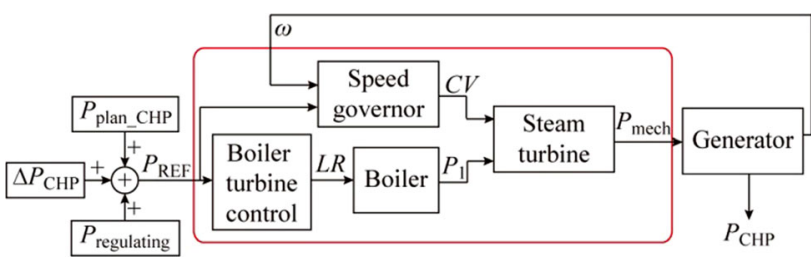

Fig. 2 Aggregated CHP model steam flow. The primary response capability is reflected through the speed governor action, which modifies the valve position of the steam turbine, according to its droop characteristic.

\subsubsection{Decentralized combined heat and power plant (DCHP)}

An aggregated generic model for DCHP power plant is developed for long term dynamic simulation studies based on the study in [15]. The model contains a speed governor and a gas turbine, as shown in Fig. 3. The droop characteristics of the speed governor govern the primary response.

In the gas turbine model, the power limitation block provides the physical restriction on turbine response and the excessive firing during ramping. The power distribution block represents the physical characteristics of fuel flow, air flow and allowable temperature. While, gas turbine dynamics block is included to represent the physical dynamics of combustion chambers and air compressor.

\subsubsection{Wind power plant (WPP)}

At the power system level, the aggregate performance of a large number of wind turbines is more important than the details of an individual wind turbine. In this study, a simplified aggregated WPP model is developed for long term dynamic simulation studies based on the IEC 61400-27-1 recommendations [16], and further simplified for the secondary active power control purpose, for each part of the Danish power system.

The aggregated WPP model, shown in Fig. 4, has a hierarchy structure, namely that there is WPP active power control level and a wind turbine (WT) active power control level. The power reference $P_{\text {ref_wT }}$ to the WT active power controller is generated by the WPP active power controller, based on the primary response signal $\left(\Delta P_{\mathrm{c}}\right)$, the reference power signal $\left(P_{\text {ref_demand }}\right)$ from the power balancing model and the measured power in the point of common connection (PCC). The $P_{\text {ref_demand }}$ depends on the required secondary response $\left(\Delta P_{\mathrm{WPP}}\right)$ from the $\mathrm{AGC}$ and the available wind power signal $\left(P_{\mathrm{WPP} \_a v a i l}\right)$ from the power balancing model. The control both in the WT and in the WPP level is realised by using PI controllers, for example, the PI controller in the WPP active power controller reduces the error between measured power at PCC ( $\left.P_{\text {meas_PCC }}\right)$ and the sum between the reference power and the primary response signal $\left(P_{\text {ref_demand }}\right.$ and $\left.\Delta P_{\mathrm{c}}\right)$, in the decision of the $P_{\text {ref_WT. }}$. Based on $P_{\text {ref_WT }}$ and $P_{\text {meas_PCC, }}$, the WT controller and generator simulates the relevant dynamic response of the WPP. 


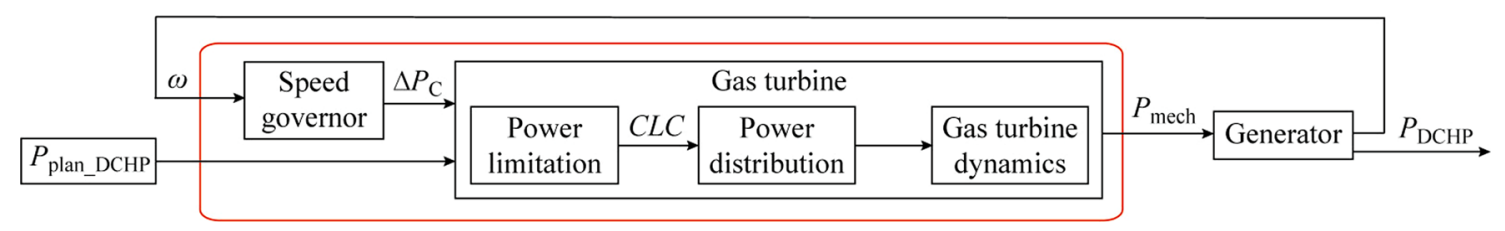

Fig. 3 Aggregated DCHP model

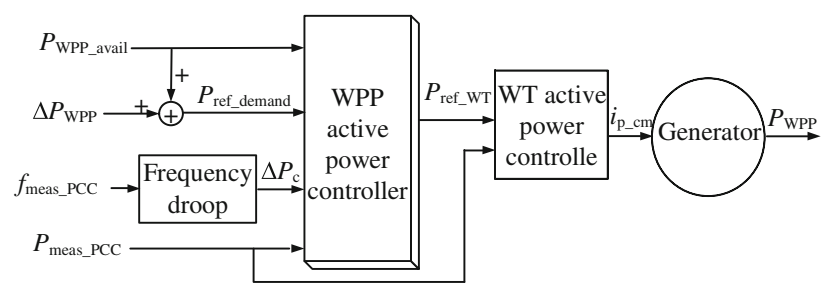

Fig. 4 Aggregated WPP model

\section{Power system operation}

The TSOs have to maintain the active power in balance in any operating condition. They utilize and combine information from different simulation programs to ensure the power balance in power system. These programs provide information regarding wind power forecast, load demand and also simulates the regulating power plan for balanced power system. Simulation power Balancing ( $\mathrm{SimBa}$ ) is such kind of power balancing program that is used to simulate HA regulating power plan for the Danish power system [17].

As illustrated in Fig. 5, SimBa uses inputs from DA market model and wind power forecast model, i.e. Wind Power Integration in Liberalised Electricity Markets (WILMAR) and Correlated Wind power fluctuations (CorWind) respectively [17]. The WILMAR provides hourly values for energy production, load and the power exchange between interconnected areas $\left(P_{\text {plan_DA }}\right)$, while CorWind provides the DA $\left(P_{\mathrm{WPP} \_\mathrm{DA}}\right)$ and HA $\left(P_{\mathrm{WPP} \_\mathrm{HA}}\right)$

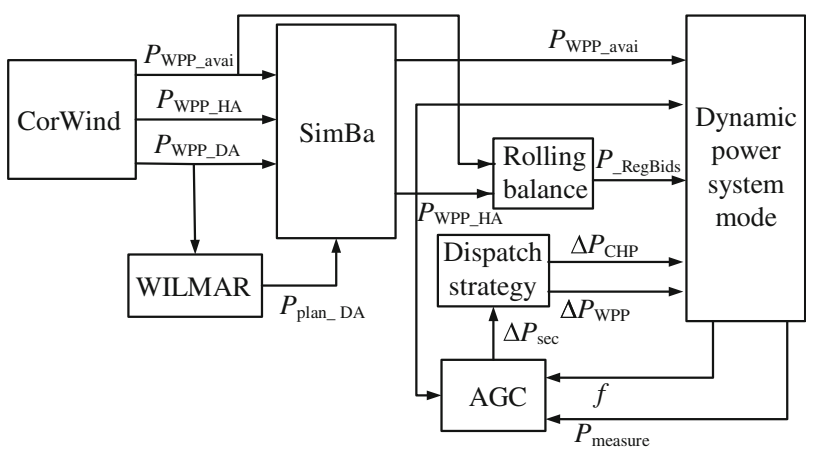

Fig. 5 Overview of the signals between CorWind, WILMAR, SimBa, dynamic power system model, rolling balance, AGC and the dispatch strategy forecasts of wind power and the available wind power $\left(P_{\mathrm{WPP} \_a v a i l}\right)$. SimBa estimates the possible wind power schedule within the operating hour based on $P_{\mathrm{WPP} \_\mathrm{HA}}$ and balances the power system internally, while taking the current grid regulations and the energy market rules continuously into account. SimBa creates a list of regulating bids based on the marginal cost function, bidding price and production capacity for each unit and provides the $5 \mathrm{~min}$ resolution plan $\left(P_{\text {plan_HA }}\right)$ for generating units and power exchange with neighbouring power systems. It is worth mentioning that SimBa while activating the bids also takes the ramping of generating units (i.e. $30 \mathrm{MW} / \mathrm{min}$ considered in this study) and the power exchange into account. The Nordic and CE power systems ramps the agreed power exchange in 30 and $10 \mathrm{~min}$, respectively. The power exchange starts $5 \mathrm{~min}$ and $15 \mathrm{~min}$ before the agreed exchange hour in CE power system and in the Nordic power system, respectively [18].

In this study, power mismatch between generation and load appears from the HA balanced power system, if the actual wind power generated within the operating hour differs from the forecast. In order to maintain the balance power system operation within the operating hour, the speed governors instantly provides the primary response and then the AGC along with rolling balance compensates the power imbalance.

\subsection{Automatic generation control (AGC)}

AGC is used to routinely balance the power system and makes its operation more reliable [18]. Traditionally conventional power plants provide the secondary frequency control in real time operation. However, the increasing wind power integration may require active participation from WPPs in secondary frequency control in future power systems along with conventional power plants, as some conventional power plants might be replaced by WPPs. Coordinated AGC with dispatch between conventional power plants and WPPs is therefore of high priority for operational security and stability.

The AGC, developed and implemented in this study, is sketched in Fig. 6. The "area control error" $\left(P_{\mathrm{ACE}}\right)$ calculation is based on the power exchange deviation from its scheduled $(\Delta P)$ and the frequency deviation $(\Delta f)$ from its nominal value, as shown in (1) and (2). The frequency bias 


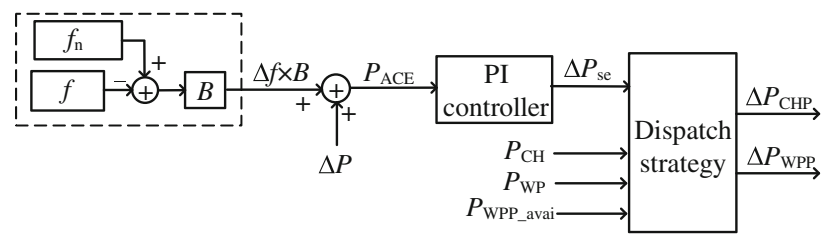

Fig. 6 AGC model

setting " $B$ " of the AGC, in (1), depends on overall droop characteristics of the generating units taking part in the primary response.

$P_{\mathrm{ACE}}=\Delta P+(\Delta f \times B)$

$\Delta P=P_{\text {exchange }}-P_{\text {exchange } \_ \text {HA }}$

The central controller, usually a proportional integral (PI), process the $P_{\mathrm{ACE}}$ and calculates the required change in production $\left(\Delta P_{\mathrm{sec}}\right)$. The change in production, based on the below equation, is then distributed through "dispatch strategy" block among the participating generators, i.e. CHP and WPP in this study.

$\Delta P_{\mathrm{set}}=-K P_{\mathrm{ACE}}-\frac{1}{T} \int P_{\mathrm{ACE}}$

Unlike the traditional AGC, the coordinated dispatch between CHP and WPP is performed in this study. The dispatch is based on the assumption that the wind power is down regulated only when CHPs are unable to down regulate their production in case of generation excess, e.g. CHPs are operating on their lower generation level $(20 \%$ of the online capacity) or AGC dispatch for the CHPs $\left(\Delta P_{\mathrm{CHP}}\right)$ touches the minimum limit. Otherwise, the WPPs will generate the available wind power and only CHPs will participate in up regulation process. The $\Delta P_{\mathrm{CHP}}$ is limited to $\pm 90 \mathrm{MW}$ within the dispatch strategy block, as it is the case for the AGC acting on the border of Western Denmark with Germany. The WPPs will follow the AGC command to safe guard secure power system operation and if necessary will down regulate its production to the minimum operating point.

\subsection{Rolling balance control}

Rolling balance is designed to simulate the actions similar to the control room, to activate the regulating power bids $\left(P_{- \text {RegBids }}\right)$ within the real-time for balanced power system operation. The real time power imbalance in the Eastern and Western Danish power systems is shown in Fig. 7. Equation (4) calculates the power imbalance in this study, taking into account the HA schedule for conventional generation and power exchange (import and export power), available wind power generation and load demand,

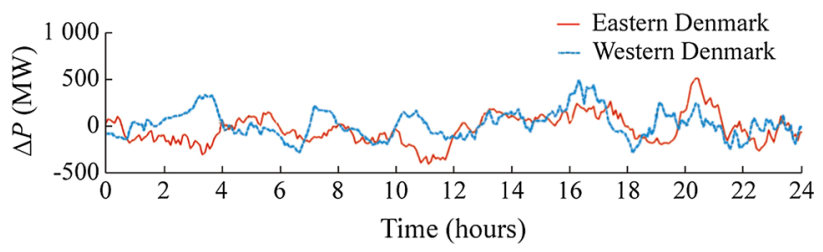

Fig. 7 Power imbalance in Danish power system

which is assumed to be equal to the HA forecast. However in real engineering, the control operator can estimate the load demand with very short term load forecasting technique [19] and system data from the SCADA/EMS. The operator after obtaining system data calculates the former forecasting error and then precisely estimates the load demand from the predicted loading in a $5 \mathrm{~min}$ resolution. The estimated load demand can then be used for calculating the power imbalance.

$$
\begin{aligned}
P_{\text {imbalance }}= & P_{\text {conventional_HA }}+P_{\text {Imports_HA }}-P_{\text {Exports_HA }} \\
& +P_{\mathrm{WPP} \_ \text {avail }}-P_{\text {Load }}
\end{aligned}
$$

The power imbalance is either caused due to forecast error (wind power/load) or other non-contingent events. In this study, the reason for power imbalance is the wind power forecast error, as illustrated in Fig. 8 by comparing the power imbalance with HA wind power forecast error. The HA wind power forecast is calculated as:

$P_{\mathrm{HA} \_ \text {error }}^{\mathrm{WPP}}=P_{\mathrm{WPP} \_ \text {avail }}-P_{\mathrm{WPP} \_\mathrm{HA}}$

The rolling balance uses the power imbalance as an input time series and will activate the regulating bids to alleviate the imbalances as effectively as possible. Before activating the regulating bids it has to ensure that the imbalance is greater than the threshold level and persistent as well, so that the algorithm does not react excessively. In this study, if the power imbalance is greater than the $30 \mathrm{MW}$ and persists for $15 \mathrm{~min}$ (i.e. three $5 \mathrm{~min}$ period), the rolling balance will activate the regulating bid equal to the minimum of the power imbalance in the start of third period, i.e. after the AGC response. The following rule is applied in activating the regulating bid:

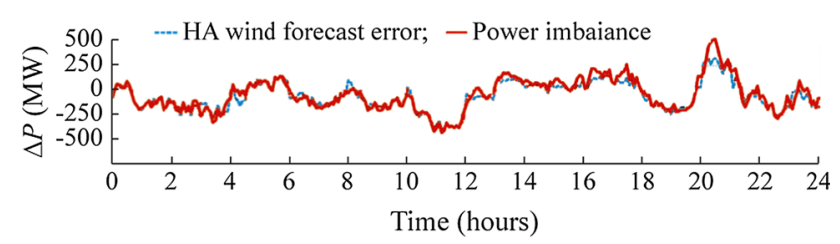

Fig. 8 Power imbalance and HA wind forecast error 
if, $\Delta p(i)>\varepsilon \& \Delta p(i-1)>\varepsilon \& \Delta p(i-2)>\varepsilon$

$\Rightarrow$ activate bids equal to

$\min (\Delta p(i), \Delta p(i-1), \Delta p(i-2))$

else, $\Delta p(i)<-\varepsilon \& \Delta p(i-1)<-\varepsilon \& \Delta p(i-2)<-\varepsilon$

$\Rightarrow$ activate bids equal to

$\max (\Delta p(i), \Delta p(i-1), \Delta p(i-2))$

where $\varepsilon$ is the threshold level and $\Delta p(i)$ is the power imbalance at time period ' $i$ '.

If the imbalance in the first group of points met the aforementioned criteria, the regulating bid equal to the smallest power imbalance of the three consecutive points is activated with a ramp rate of $30 \mathrm{MW} / \mathrm{min}$ and the new points are checked. If the second group of points is also found to meet the criteria, then again the regulating bid is activated. But if one of these points does not meet the criteria, then the regulating bid is not activated. Figure 9 shows the regulating power activated in Eastern and Western Danish power systems by the rolling balance algorithm for an imbalance shown in Fig. 7 .

The coordination between aforementioned power balance control schemes is demonstrated in Fig. 10, where primary response, AGC response and rolling balance are timely disassociated. Following the power imbalance, the power plants equipped with the speed governors provides the initial support by releasing the primary reserves within $30 \mathrm{~s}$. Afterwards, the AGC provides the secondary control by ramping the power generation from the participating power plants. The response of the AGC depends on the time delays associated with the AGC system, CHP and WPP. In this study, the secondary response is provided within 7-8 $\mathrm{min}$. The rolling balance activates the regulating power at the start of third period $\left(10^{\text {th }} \mathrm{min}\right)$, if the power imbalance is persistent for three periods and greater than threshold level. The activation of regulating power through rolling balance will also restores the secondary reserves, depending on the remaining power imbalance.
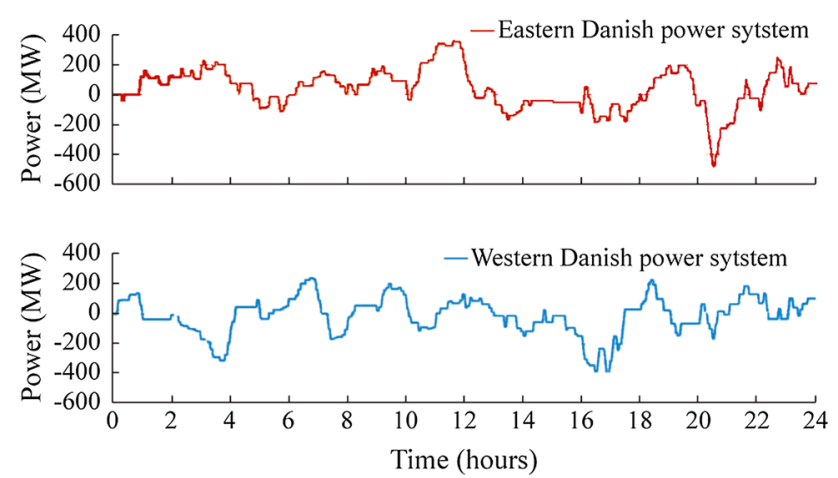

Fig. 9 Regulating power activated in Eastern \& Western Danish power systems

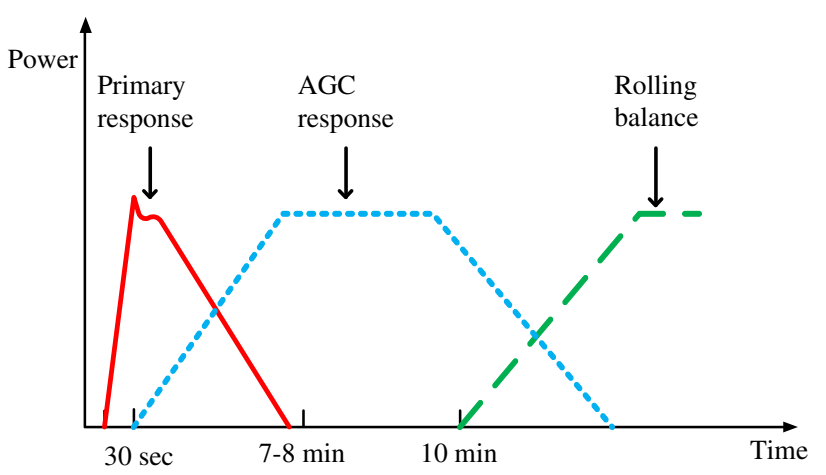

Fig. 10 Proposed real-time balance control

The real-time power balancing concept provided above activates the regulating power while taking in account the maximum and minimum limits on generating units, dispatch limits and the generation cost. However, to implement the above concept, in addition to the above constraints, the coordinated AGC and rolling balance must also take the transmission constraints in account.

\section{Simulations and results}

A set of simulations has been carried out to illustrate the performance of the power system model on the focus of active power balanced control. The simulations are performed using the time series for generation, load and power exchange generated by HA power balancing model (SimBa) for the Danish power system and are the assumptions for the year 2020 based on the real data from the year 2009. The conventional generation and the power exchange are using HA time series, while WPP generates the available wind power. Power imbalance appears within the operating hour, if HA wind power forecast is not the same as available wind power. This imbalance is compensated by AGC and by activating the regulating bids from CHPs within the operating hour by an algorithm (rolling balance), developed for this study.

The motivation to investigate the system behaviour on the considered day is the availability of wind power and high load demand in a large scale wind power integrated power system. The availability of wind allows the WPPs to generate more power than conventional power plants and also positive power exports with neighbouring power systems. The power exports are calculated by subtracting the total export power from total import power with neighbouring power systems. On the specific day in Eastern Denmark, the conventional power plants generated 33.31 GWh of electricity, while WPPs generated $43.2 \mathrm{GWh}$, i.e. $56.46 \%$ of the total electricity production. 
The high production from WPPs allows the power exports of $32.75 \mathrm{GWh}$ from Eastern Danish power system, when the load demand was $43.75 \mathrm{GWh}$. Similarly in Western Denmark, $45.77 \mathrm{GWh}$ is generated from conventional power plants and $59.53 \mathrm{GWh}$ from WPP, i.e. $56.53 \%$. While, the total load demand and the power exports are 63.98 GWh and $41.27 \mathrm{GWh}$, respectively. It can also be noted that on specific day, WPP contributed $98.7 \%$ and $93 \%$ of the total load demand in Eastern and Western Danish power system, respectively.

As aforementioned, the HA wind forecast error will create an imbalance between generation and load demand within the operating hour, thus deviating the system frequency from its nominal level. In response, the speed governors instantaneously release the primary reserves and balance the system frequency at new level. The deviation in frequency from its nominal level will also diverge the power exchange with from its schedule. To return the system frequency to its nominal level and power exchange to its schedule, the AGC provides the secondary response. The AGC responds to the area control error $\left(P_{\mathrm{ACE}}\right)$ with $\Delta P_{\text {sec }}$ and then distribute it among the participating generators through secondary dispatch block. The $\Delta P_{\text {sec }}$ lags behind $\Delta P_{\mathrm{ACE}}$, due to the delays in AGC system and the delays associated with the power plants response which does not allow the units to change their output as $\Delta P_{\mathrm{ACE}}$. These delays are due to the ramp in the reference power and also due to the slow boiler response of CHP units, as boiler needs 5-6 min to modify its output pressure when demanded.

The secondary dispatch provides new set points to the CHP and WPP, based on the operating conditions of CHP and WPP and also on the available wind power. The secondary dispatch to the CHP $\left(\Delta P_{\mathrm{CHP}}\right)$ and WPP $\left(\Delta P_{\mathrm{WPP}}\right)$ is shown in Fig. 11, where the WPPs only participate in the down regulating process, while CHPs contributes in both

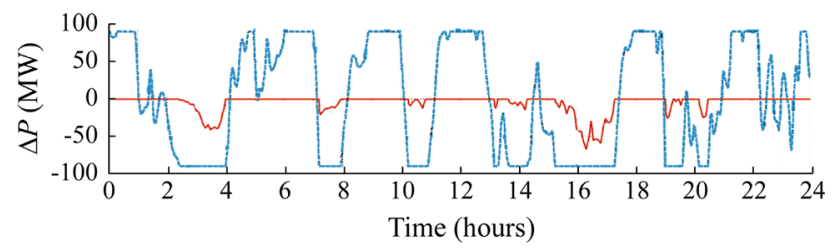

(a) Eastern Danish power system

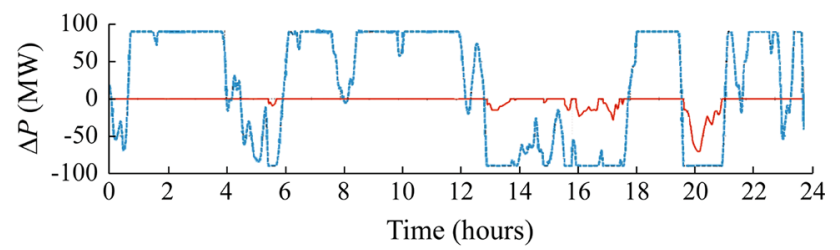

(b) Western Danish power system

$$
\Delta P_{\mathrm{CHP}} ;-\Delta P_{\mathrm{WPP}}
$$

Fig. 11 Secondary dispatch up and down regulating processes. The $\Delta P_{\mathrm{CHP}}$ is limited by $\pm 90 \mathrm{MW}$, as the case of AGC in Western Danish power system. The down regulating secondary dispatch to the WPPs is activated only when CHPs are unable to provide the required response, i.e. the $\Delta P_{\mathrm{CHP}}$ reaches $-90 \mathrm{MW}$ or they are operating at their lower limit $(20 \%$ of the online capacity). The AGC controlled WPP then reduces the real time power imbalance in the Danish power system by down regulating its production. Notice that the $\Delta P_{\mathrm{WPP}}$ is seldom activated, only when CHP are not able to down regulate their production.

In order to reduce the real time power imbalance and restores the secondary reserves, the rolling balance activates the regulating bids where the process is almost similar to the control room operator's response. The rolling balance activates the bids if the imbalance is greater than threshold level (30 MW considered for this study) and persists for three periods, i.e. $15 \mathrm{~min}$. The regulating bid is activated at the start of third period and equals to the minimum imbalance of three consecutive periods, while the AGC directly responds to the power imbalance. The regulating power activated by the rolling balance is already shown in Fig. 9. The resulting AGC dispatch after the activation of regulating power is shown in Fig. 12 and it can be noticed that the rolling balance restores some of the secondary reserves and thereby reduces the regulating burden on AGC.

Activating the regulating bids through rolling balance not only reduces the real time active power imbalance but makes the power system operation more reliable and secure. Figure 13 compares the power imbalance in the Danish power system, when:

a. Real-time control is provided with coordinated AGC and rolling balance

b. Real-time control is provided with coordinated AGC

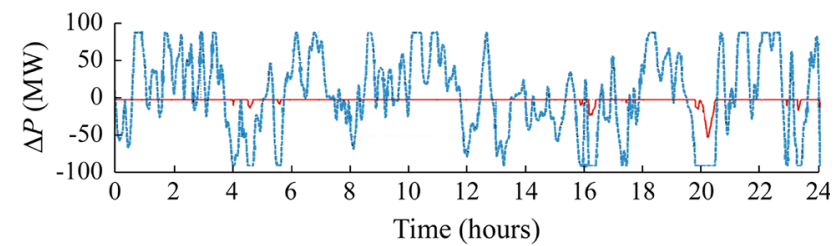

(a) Eastern Danish power system

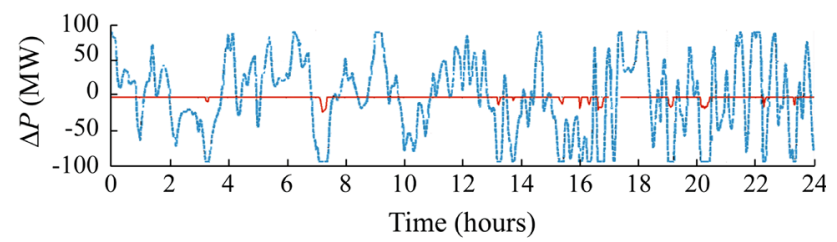

(b) Western Danish power system $-\Delta P_{\mathrm{CHP}} ;-\Delta P_{\mathrm{WPP}}$

Fig. 12 Secondary dispatch with rolling balance 


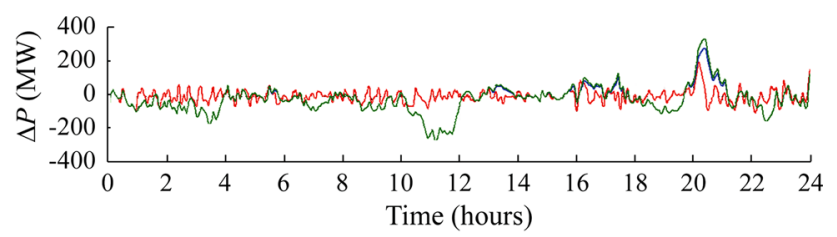

(a) Eastern Danish power system

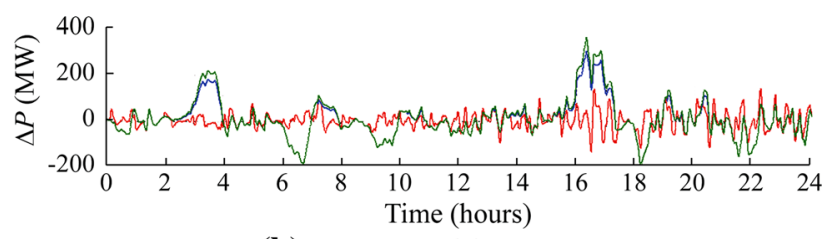

(b) Western Danish power syster $\rightarrow \mathrm{A} ;-\mathrm{B} ;-\mathrm{C}$

Fig. 13 Power imbalance

c. Real-time control is provided with conventional AGC, when only CHP provides support

It can be noticed that the power imbalance has decreased substantially with the proposed active power balance technique, i.e. when real-time control is provided with coordinated AGC and rolling balance. The conventional AGC also reduces the power imbalance in real-time, but the programmed activation of regulating bids and coordinated AGC assures the reliable operation of highly wind power integrated power system.

\section{Conclusion}

Regulating power in a deregulated power system is always needed to increase system reliability and to ensure power supply security. The need for regulating reserves is growing with the increase of wind power integration in power systems. Beside this, effective way of bids activation is also of high importance. In this article, an algorithm has been designed in order to simulate the actions similar to the control room with respect to real time active power balance control. The algorithm 'rolling balance' is exemplified and implemented for the case of a power system that reflects the dynamics of the future Danish power system with a high wind penetration scenario. The dynamic model of a power system uses input time series from an hourahead power balancing model ( $\mathrm{SimBa}$ ) for power generation, load demand and power exchange corresponding to one particular day with high wind speed and high load demand.

The studies performed and presented in this article illustrate how power imbalances between load and generation, caused by wind power forecast error can be compensated effectively by the automatic activation of regulating power bids from conventional power plants and also by regulating the active power production from combined heat and power plants and wind power plants. The rolling balance is designed to activate the regulating bids while the coordinated automatic generation control provides the required secondary response from combined heat and power plants and wind power plants.

The importance of the regulating bids and of their effective activation for a reliable and secure operation of large wind power integrated power system has been demonstrated though the present investigation. The activation of the regulating reserves through the rolling balance efficiently reduces the real time imbalances and thereby ensuring reliable power system operation. Furthermore the wind power plant integrated coordinated automatic generation control ensures the secure power system operation. However, better forecasting of wind speed and the load demand is still desirable for operational security of highly wind power integrated power system.

Acknowledgement This paper is a part of Ph.D. project funded by Sino-Danish centre for education and research (SDC).

Open Access This article is distributed under the terms of the Creative Commons Attribution 4.0 International License (http:// creativecommons.org/licenses/by/4.0/), which permits unrestricted use, distribution, and reproduction in any medium, provided you give appropriate credit to the original author(s) and the source, provide a link to the Creative Commons license, and indicate if changes were made.

\section{References}

[1] Sørensen P, Norheim I, Meibom P et al (2008) Simulations of wind power integration with complementary power system planning tools. Electr Power Syst Res 78(6):1069-1079

[2] Doherty R, Mullane A, Nolan G et al (2010) An assessment of the impact of wind generation on system frequency control. IEEE Trans Power Syst 25(1):452-460

[3] Ummels BC, Gibescu M, Kling WL et al (2007) Performance of automatic generation control mechanisms with large-scale wind power. In: Proceedings of the Nordic wind power conference (NWPC'07), Roskelde, 1-2 Nov 2007, 7 pp

[4] Li BH, Hong S, Yong T et al (2011) Study on the frequency control method and AGC model of wind power integration based on the full dynamic process simulation program. In: Proceedings of the 2011 international conference on power system automation and protection (APAP'11), vol 1, Beijing, 16-20 Oct 2011, pp 246-251

[5] Antonishen MP, Hai HY, Brekken TKA et al (2012) A methodology to enable wind farm participation in automatic generation control using energy storage devices. In: Proceedings of the Power and Energy Society general meeting, San Diego, 22-26 Jul 2012, 7 pp

[6] Zhu JZ, Cheung K (2009) Analysis of regulating wind power for power systems. In: Proceedings of the Power and Energy Society general meeting, Calgary, 26-30 Jul 2009, 6 pp

[7] Vittrup C (2014) 2013 was a record-setting year for Danish wind power. Energinet.dk, Errits $\emptyset$ 
[8] Basit A, Hansen AD, Sorensen P (2013) Dynamic model of frequency control in Danish power system with large scale integration of wind power. In: Proceedings of the 2013 China wind power conference (CPW'13), Beijing, 16-18 Oct 2013

[9] Rebours YG, Kirschen DS, Trotignon M et al (2007) A survey of frequency and voltage control ancillary services-Part I: technical features. IEEE Trans Power Syst 22(1):350-357

[10] Skødt T (2012) Electricity interconnections. Energinet.dk, Errits $\varnothing$

[11] Policy 1 (2009) Load-frequency control. European Network of Transmission System Operators for Electricity (ENTSO-E), Brussels

[12] Norheim I, Lindgren E, Uski S et al (2006) WILMAR—system stability analysis. WILMAR Deliverable D5.1, No. SINTEFTR-F6212

[13] Working Group on Prime Mover and Energy Supply Models for System Dynamic Performance Studies (1991) Dynamic models for fossil fueled steam units in power system studies. IEEE Trans Power Syst 6(2):753-761

[14] Byerly RT, Aanstad O, Berry DH et al (1973) Dynamic models for steam and hydro turbines in power system studies. IEEE Trans Power Apparatus Syst 92(6):1904-1915

[15] Pourbeik P, Baba Z, Boyer R et al (2003) Modeling of gas turbines and steam turbines in combined-cycle power plants. CIGRE Technical Brochure 238, CIGRE, Paris

[16] IEC 61400-27-1:2015 Wind turbines, Part 27-1 (2015) Electrical simulation models for wind power generation

[17] Giannopoulos G (2012) Frequency control in area with large scale wind power. Master Thesis, Technical University of Denmark, Roskilde

[18] Continental Europe operation handbook-P1 (2009) Load-frequency control and performance. European Network of Transmission System Operators for Electricity (ENTSO-E), Brussels

[19] Liu K, Subbarayan S, Shoults RR et al (1996) Comparison of very short-term load forecasting technique. IEEE Trans Power Syst 11(2):877-882

Abdul BASIT received the B.Sc. degree in electrical engineering from the University of Engineering \& Technology, Peshawar,
Pakistan in 2006, M.Sc. degree in electrical power engineering from Chalmers University of Technology, Sweden in 2011, and Ph.D. degree from Technical University of Denmark (DTU). He is currently working as Assistant Professor at University of Engineering \& Technology, Peshawar, Pakistan. His research interest includes integration of wind power into power systems, automatic generation control, wind power plant control, and power systems control.

Anca D. HANSEN received the degree in aerospace engineering from the Technical University of Bucharest, Romania, in 1992 and a Ph.D. degree in modelling and control engineering from Denmark Technical University in 1996. In 1998, she joined Risø National Laboratory, working first as PostDoc and then a scientist with modelling and control of wind turbines. Today, she is working as Senior Scientist in the DTU Wind Energy department, former Ris $\emptyset$ National Laboratory, in Denmark. Her research interest is integration of wind power into power systems, involving different technical topics on dynamic modelling and control of wind power plants, ancillary services as well as power system control and stability topics. She is author or co-author of more than 100 journal/conference papers, several research reports in her research fields.

Poul E. SØRENSEN was born in 1958. He received the M.Sc. degree in electrical engineering from the Technical University of Denmark, Copenhagen, Denmark, in 1987. Since 1987, he has been at Ris $\varnothing$ National Laboratory, Roskilde, where he is currently a Professor. His research interests include integration of wind power into power systems, involving a variety of technical disciplines including power system control and stability, dynamic modeling and control of wind turbines and wind farms, and wind fluctuation statistics. Prof. Sørensen is convener of the IEC 61400-27 working group.

Georgios GIANNOPOULOS received the bachelor's degree in electrical and computer engineering from University of Paras in 2010 and obtained his MSc degree in wind energy from Technical university of Denmark in 2012. He is currently working as Research and Development Project Engineer at Elia, Belgium. 